J. Lake Sci. (湖泊科学), 2021, 33(4): 1043-1050

DOI 10. 18307/2021. 0407

(c) 2021 by Journal of Lake Sciences

\title{
巢湖水华蓝藻原位生长率的时空变化及其环境影响因子"
}

\author{
阳 振, 史小丽, 陈开宁, 张 民** \\ (中国科学院南京地理与湖泊研究所, 湖泊与环境国家重点实验室, 南京 210008)
}

\begin{abstract}
摘 要: 原位生长率是研究藻类生长、衰亡、种群演变、生产力估算, 以及藻类对环境变化响应的重要指标,针对水华蓝藻 原位生长率的测定, 目前还缺乏成熟可靠的手段. 本研究利用改进的原位培养法, 根据培养前后藻蓝素浓度的变化, 对巢 湖东、中、西 3 个湖区水华蓝藻的原位生长率进行周年调查. 结果表明, 巢湖水华蓝藻的原位生长率变化范围在-1.16 $0.69 \mathrm{~d}^{-1}$ 之间, 表层的原位生长率最高, 中层次之, 底层大部分月份都为负值; 原位生长率在空间分布上由高到低依次为西 部湖区 > 中部湖区 >东部湖区; 在季节变化上, 原位生长率春季 (4-6月) 相对较高, 冬季 (1-2 月) 相对较低. 与环境因子 进行相关分析后发现, 原位生长率与溶解性总磷和温度正相关, 这表明溶解性总磷和温度可能是影响巢湖水华蓝藻原位 生长率的重要环境因子.
\end{abstract}

关键词: 原位培养; 原位生长率; 营养盐;温度;藻蓝素;巢湖

\section{Spatial-temporal variations of the in-situ growth rate of bloom-forming cyanobacteria and their environmental factors in Lake Chaohu, China*}

Yang Zhen, Shi Xiaoli, Chen Kaining \& Zhang Min **

( State Key Laboratory of Lake Science and Environment, Nanjing Institute of Geography and Limnology, Chinese Academy of Sciences, Nanjing210008, P.R.China)

Abstract: In-situ growth rate is an important parameter for algae to study their growth, death, population variation, productivity and response to environmental changes. Currently, there is a lack of mature and accurate method to determine the in-situ growth rate of bloom-forming cyanobacteria. In this study, an improved in-situ incubation method base on the change of phycocyanin were used to investigate the annual net in-situ growth rate of bloom-forming cyanobacteria in the eastern, central and western lake areas of Lake Chaohu. The results showed that the net in-situ growth rate of bloom-forming cyanobacteria ranged from -1.16 to $0.69 \mathrm{~d}^{-1}$. The growth rates in the surface layer were higher than those in the middle layer, and those in the bottom layer were the lowest and negative in most months. In terms of spatial distribution, the growth rates from high to low were the eastern, central and western lake areas. The growth rates were the highest in spring (April to June) and the lowest in winter (January to February). Spearman correlation analysis showed that growth rate was positively correlated with dissolved total phosphorus (DTP) and temperature, which indicates that DTP and temperature are the key environmental factors affecting the in-situ growth rate of bloom-forming cyanobacteria in Lake Chaohu.

Keywords: In-situ incubation; in-situ growth rate; nutrient; temperature; phycocyanin; Lake Chaohu

水华蓝藻在大型富营养湖泊中经常会随风向和湖流在不同湖区间发生迁移,通过色素含量、细胞密度 等常规生物量参数的监测, 只能获得蓝藻时空分布的一些表观信息. 原位生长率是研究藻类生长、衰亡、种 群演变、生产力估算, 以及对环境变化响应的重要指标,也是预测蓝藻水华未来发展趋势并构建水华预测模 型的必要参数. 利用原位生长率能准确评估蓝藻在不同湖区的生长状态和生长潜力, 并据此制定出针对性

* 2020-08-24 收稿;2020-10-20 收修改稿.

国家水体污染控制与治理科技重大专项 (2018ZX07208-004)、国家自然科学基金项目 (31971476, 31570457) 和中 国科学院南京地理与湖泊研究所“一三五”项目 (NIGLAS2018GH01) 联合资助.

** 通信作者;E-mail: mzhang@ niglas.ac.cn. 
的水体治理和水华控制策略.

目前常用的藻类原位生长率测定方法主要有原位培养法 ${ }^{[-2]}$ 、光合速率计算法 ${ }^{[-4]}$ 、细胞分裂频率

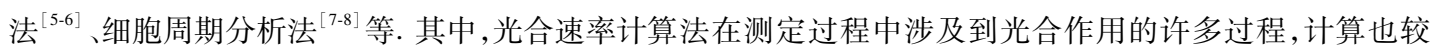
为复杂, 且只适用于具独特色素成分的类群; 细胞分裂频率法操作比较繁琐, 不同细胞分裂状态的区分缺乏 标准; 细胞周期分析法涉及到细胞周期相关蛋白和基因的定量分析难度比较大; 原位培养法通过将藻类放 人去除了捕食者的封闭容器中培养, 根据细胞数、生物体积或其它生物量指标的增加或减少来确定藻类的 表观生长速率 ${ }^{[9]}$, 但原位培养法容器内外无物质 (或能量) 交换, 易存在 “瓶壁” 效应影响 ${ }^{[10]}$. 因此, 对于水华 蓝藻原位生长率的测定, 目前还缺乏成熟可靠的手段.

巢湖位于安徽省中部, 面积约 $780 \mathrm{~km}^{2}$, 是我国五大淡水湖泊之一, 也是我国水污染防治的重点水体 ${ }^{[11]}$. 自 1970s 起, 由于流域内社会经济快速发展, 人湖污染负荷增加, 导致湖体富营养化加重, 蓝藻水华频发 ${ }^{[12]}$. 巢湖水体营养盐水平主要表现为由东向西逐步升高的状态, 水华蓝藻的空间分布也与之相似 ${ }^{[13]}$, 水华优势 种主要为微囊藻和鱼腥藻, 夏、秋季以微囊藻为主, 春、冬季鱼腥藻比例升高 ${ }^{[14]}$. 蓝藻的生长受温度、光强、 营养盐等多种环境因素的影响, 由于巢湖不同湖区在物理、化学、生物等方面都存在着差异, 蓝藻在不同湖 区会呈现出不同的生长状况和生长潜力. 为获取巢湖不同湖区和季节的蓝藻原位生长率, 以及影响蓝藻原 位生长率的主要环境因子, 本研究利用改进的原位培养法, 对巢湖蓝藻原位生长率进行周年观测, 以期为巢 湖蓝藻水华的预测和防控提供数据支撑.

\section{1 研究方法}

\section{1 野外调查研究}

野外研究于 2019 年 4 月- 2020 年 3 月每月中旬进行, 为期 $1 \mathrm{~d}$, 在巢湖设置 3 个研究位点, 具体位置见 图 1, 其中, W 位点位于西部湖区, C 位点位于中部湖区, E 位点位于东部湖区. 每个研究位点在现场利用 U50 多参数水质仪 (HORIBA, Kyoto, Japan) 原位测定水温、溶解氧 ( DO) 、 $\mathrm{pH}$ 等环境因子. 同时, 用采水器采 集表层、中层、底层水样混合, 取 $200 \mathrm{~mL}$ 水样放人冷藏箱中, 用于营养盐、藻蓝素等参数的分析. 取 $1000 \mathrm{~mL}$ 水样装人原位培养装置, 将装置用绳子系好放人湖中, 分别置于水柱表层、中层、底层, 考虑到现场实验条 件, 在每个点位的各层只设置了 1 个培养装置. 原位培养装置由透明有机玻璃圆管改造而成, 内径 $12 \mathrm{~cm}$, 高 $10 \mathrm{~cm}$, 容积约为 $1130 \mathrm{~mL}$, 顶部和底部固定有孔径为 5000 目 $(5 \mu \mathrm{m})$ 的尼龙篮网, 在允许培养装置内外物质

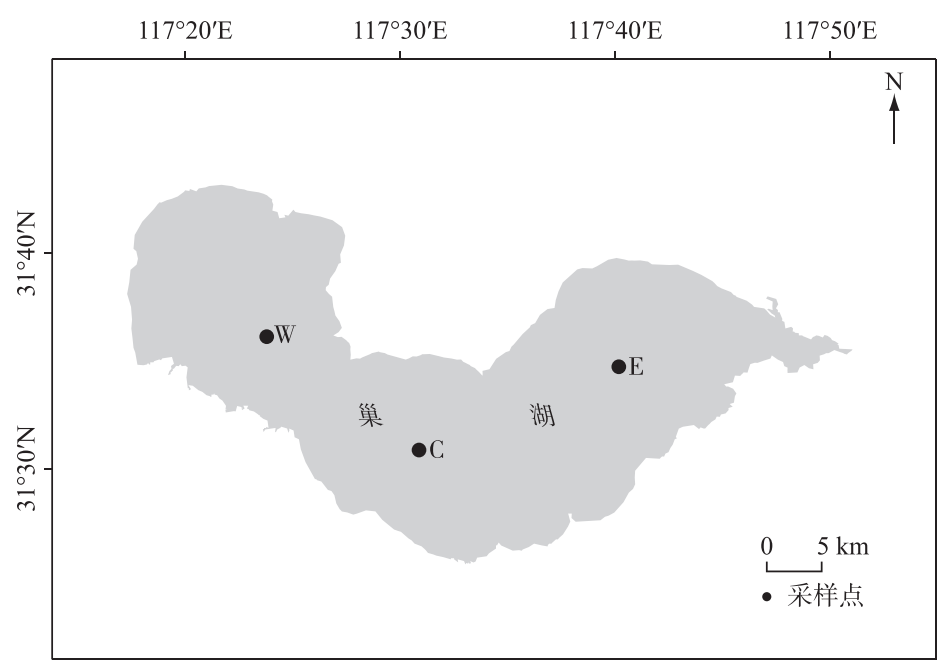

图 1 巢湖水华蓝藻原位生长率研究位点分布 ( W : 西部湖区; $\mathrm{C}$ : 中部湖区; $\mathrm{E}$ : 东部湖区)

Fig.1 Sampling sites for the in-situ growth rate of bloom-forming cyanobacteria in Lake Chaohu (W: Western lake area; C: Central lake area; E: Eastern lake area) 
交换的同时,又能够阻隔绝大部分水华蓝藻细胞穿过 (虽然 部分微囊藻种类的单细胞直径小于 $5 \mu \mathrm{m}$, 但野外微囊藻以 群体为主, 单细胞微囊藻占比非常少), 圆管侧面有一阀门 用于水样加人、取出以及绳子固定 (图 2), 培养装置在水中 时阀门朝上,水体可沿水平方向在装置内外交换. 取样在培 养 $24 \mathrm{~h}$ 后进行, 取样后样品放人冷藏箱中, 并立即带回实验 室进行各指标测定的预处理.

\section{2 室内分析与气象数据}

溶解性总氮 (DTN, GF/C 膜滤后水) 浓度采用碱性过硫 酸钾消解一紫外分光光度法测定; 溶解性总磷 (DTP, GF/C 膜滤后水) 浓度采用碱性过硫酸钾消解一钼锑抗显色分光光

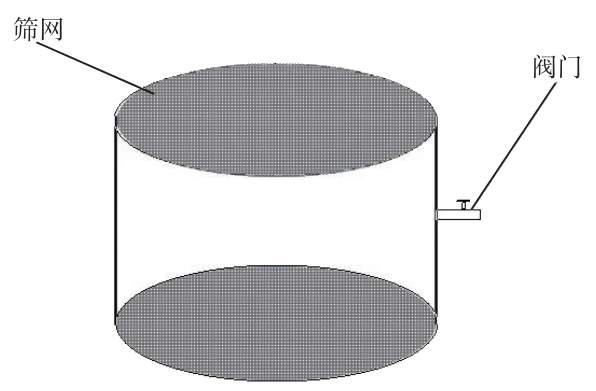

图 2 原位培养装置

Fig.2 In-situ incubation apparatus 度法测定. 取水样过滤, 滤膜经研磨后在 $4^{\circ} \mathrm{C}$ 的黑暗条件下 用 $0.05 \mathrm{~mol} / \mathrm{L} \mathrm{pH} 7.0$ 的 Tris 缓冲液提取 8 10 h, 离心后取上清液用苂光分光光度计( RF-5301PC Shimadzu, 日本) 测定藻蓝素浓度 ${ }^{[15]}$, 以表征蓝藻生物量, 测定条件为激发波长 $620 \mathrm{~nm}$, 发射波长 $647 \mathrm{~nm}$, 以藻蓝素标 准品溶液制作标准曲线. 日平均温度、降雨量和日照时间等气象数据为合肥气象站 (\#58321) 观测数据, 来自 于中国气象数据网 (http://data.cma.cn).

\section{3 数据分析与统计}

原位 (比)生长率 $(\mu)$ 计算公式为:

$$
\mu=\ln \left(N_{t}-N_{0}\right) / t
$$

式中, $N_{0}$ 为初始时刻藻蓝素浓度, $N_{t}$ 为培养结束时藻蓝素浓度, $t$ 为培养时间 (本研究为 $1 \mathrm{~d}$ ).

数据统计分析采用 SPSS 16.0 软件完成, 采用 Spearman 相关分析分析表层原位生长率与各环境因子的 相关性, $P<0.05$ 代表显著相关, $P<0.01$ 代表极显著相关,使用 Origin 8.0 软件绘图.

\section{2 结果}

巢湖水体 TDN 浓度周年内波动比较大 (图 3a), 东部湖区 2-5 月相对较高, 其余月份相对较低; 中部湖 区 4 月、12-2 月浓度相对较高, 其余月份相对较低; 西部湖区 12-6 月相对较高, 其余月份相对较低; 而中 部和西部湖区 TDN 浓度大部分月份高于东部湖区. 巢湖水体 TDP 浓度时空差异表现更为明显 (图 3b), 中 部和西部湖区 TDP 浓度在 2-8 月相对较高, 其余月份相对较低, 而东部湖区 TDP 浓度年内波动较小. 在空 间上 TDP 浓度由低至高依次为东部湖区<中部湖区<西部湖区. 3 个湖区水体藻蓝素浓度均呈现夏、秋季高, 春、冬季低的趋势, 藻蓝素浓度峰值出现在 7-9 月,西部湖区峰值最高,东部湖区最低(图 3c).

蓝藻在不同水深和湖区的原位生长率差异较大 (图 4). 在表层水体, 西部湖区 9 月和 2 月原位生长率为 负值, 其余月份为正值, 最高值发生在 6 月 $\left(0.69 \mathrm{~d}^{-1}\right)$, 年平均值为 $0.29 \mathrm{~d}^{-1}$; 中湖区 $9 、 12 、 1 、 2$ 月原位生长率 为负值, 其余月份为正值, 最高值发生在 6 月 $\left(0.49 \mathrm{~d}^{-1}\right)$, 年平均值为 $0.10 \mathrm{~d}^{-1}$; 而东湖区仅 $4 、 6 、 8 、 12$ 月原位 生长率为正值, 其余月份为负值, 最高值发生在 4 月份 $\left(0.26 \mathrm{~d}^{-1}\right)$, 年平均值为 $-0.21 \mathrm{~d}^{-1}$. 在中层水体, 西湖 区原位生长率有 5 个月份为正值, 其余为负值, 年平均值为 $0.01 \mathrm{~d}^{-1}$; 中部湖区原位生长率有 3 个月份为正 值, 其余月份为负值, 年平均值为 $-0.17 \mathrm{~d}^{-1}$; 而东部湖区原位生长率仅有 2 个月份为正值, 其余月份为负值, 年平均值为 $-0.33 \mathrm{~d}^{-1}$. 在底层水体, 3 个湖区大部分月份原位生长率都为负值.

Spearman 相关分析结果表明, 藻蓝藻浓度与 DTP 浓度、温度均呈极显著正相关, 与 DTN 浓度、风速均呈 极显著负相关. 原位生长率与 DTP 浓度呈极显著正相关 $(P<0.01)$, 与温度呈显著正相关 $(P<0.05)$, 与 DO 浓度呈极显著负相关 $(P<0.01)$, 与其它环境因子相关性不高 $(P>0.05)$ (表 1$)$.

\section{3 讨论}

原位培养法是获取浮游植物原位生长率最为直接的方法. 一些研究者将室内纯培养的藻种, 加人经过 滤去除浮游生物后的湖水中, 装人培养瓶后放置在水体中原位培养 ${ }^{[16-17]}$. 但由于野外水体中的水华蓝藻种 

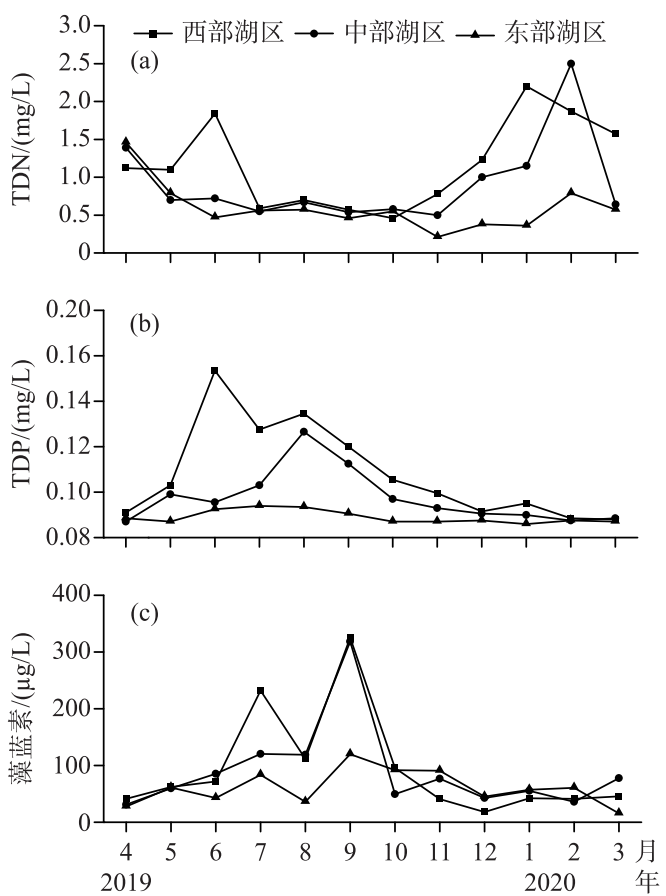

图 3 巢湖 3 个观测点 TDN 、TDP 和藻蓝素浓度的周年变化

Fig.3 Annual variation of TDN,TDP and phycocyanin concentrations in the three sampling sites in Lake Chaohu
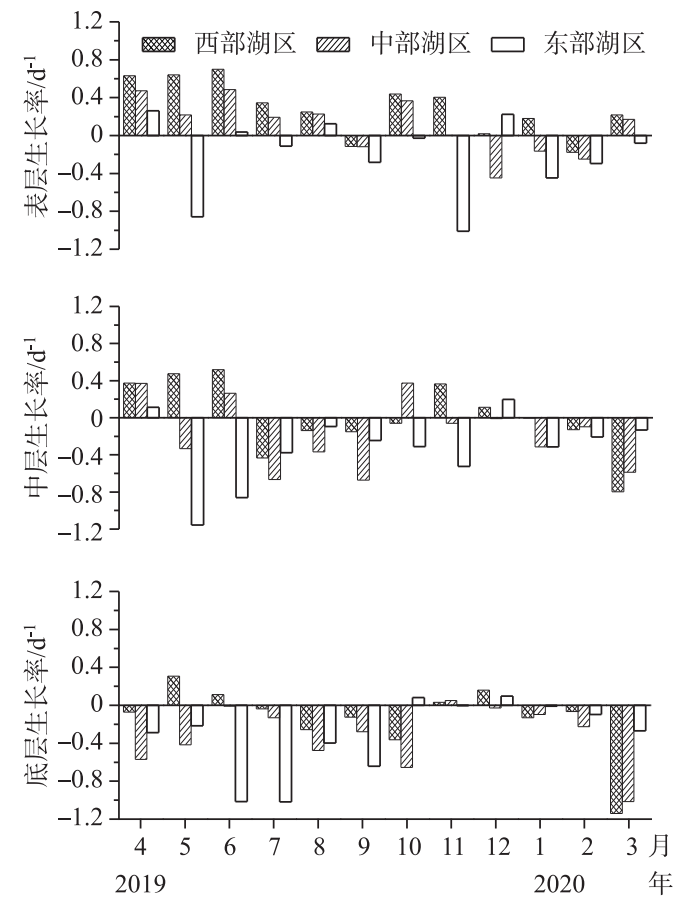

图 4 巢湖 3 个观测点水华蓝藻原位生长率的周年变化

Fig.4 Annual variation of the in-situ growth rate of bloom-forming cyanobacteria in the three sampling sites in Lake Chaohu 
表 1 水华蓝藻原位生长率与环境因子的相关系数

Tab.1 Spearman correlation analysis of the environmental factors and the in-situ growth rate of bloom-forming cyanobacteria

\begin{tabular}{|c|c|c|c|c|c|c|c|c|c|c|}
\hline & DTN & DTP & 水温 & DO & $\mathrm{pH}$ & 日照时间 & 降雨量 & 风速 & 藻蓝素 & $\mu$ \\
\hline DTN & 1.00 & & & & & & & & & \\
\hline DTP & 0.01 & 1.00 & & & & & & & & \\
\hline 水温 & -0.20 & $0.58^{* *}$ & 1.00 & & & & & & & \\
\hline DO & -0.16 & -0.28 & $-0.35 *$ & 1.00 & & & & & & \\
\hline $\mathrm{pH}$ & -0.06 & 0.09 & $0.45^{\text {** }}$ & -0.33 & 1.00 & & & & & \\
\hline 日照时间 & -0.23 & 0.22 & 0.31 & 0.02 & -0.13 & 1.00 & & & & \\
\hline 降雨量 & 0.23 & -0.37 & $-0.43^{\text {*** }}$ & -0.04 & -0.02 & $-0.53^{* *}$ & 1.00 & & & \\
\hline 风速 & 0.08 & 0.17 & 0.25 & -0.18 & 0.15 & -0.30 & -0.03 & 1.00 & & \\
\hline 藻蓝素 & $-0.51^{* *}$ & $0.43^{* * *}$ & $0.47^{* * *}$ & 0.06 & 0.12 & 0.30 & $-0.53^{* * *}$ & -0.08 & 1.00 & \\
\hline$\mu$ & 0.22 & $0.55^{* * *}$ & $0.38^{*}$ & $-0.41^{*}$ & 0.10 & 0.09 & -0.04 & 0.17 & -0.10 & 1.00 \\
\hline
\end{tabular}

*表示显著相关, ** 表示极显著相关.

类组成复杂, 不同种群和株系蓝藻在生理与形态上有较大差异, 即使在相同环境条件下也会表现出不同的 生长率 ${ }^{[18-19]}$, 因此, 利用室内纯培养的藻种往往不能获得野外原位蓝藻的真实生长率. 还有许多研究者在现 场采集湖水直接装人培养瓶进行原位培养 ${ }^{[20-21]}$, 考虑到浮游动物的捕食压力, 通常会利用稀释法改变摄食 者的浓度而间接地测算出浮游植物比生长率 ${ }^{[22-23]}$. 由于水华蓝藻群体粒径范围广, 不易用滤除的方式将其 与浮游动物分离, 且大部分水华蓝藻的群体粒径或丝状藻体均大于浮游动物的口器大小, 浮游动物对它们 的摄食率通常非常低 ${ }^{[24]}$. 因此, 本研究并没有使用稀释法或去除浮游动物后计算生长率, 而是直接通过培 养前后水华蓝藻生物量的变化来得到其净增长率. 原位培养法最大的难题是如何克服 “瓶壁” 效应,使培养 瓶内外物质交换保持通畅, 实现真正的原位培养. 本研究利用篮网将圆柱型培养瓶的上下开口密封,使培养 瓶成为一个半封闭的容器, 容器内外水体能自由交换, 绝大部分水华蓝藻细胞则无法穿过. 但由于篮网孔径 非常小, 长时间放置在水中, 篮网孔容易被水体中的颗粒物或者附着微生物所堵塞, 所以原位培养时间不宜 过长.

本研究观测到巢湖水华蓝藻的原位生长率变化范围在-1.16 0.69 $\mathrm{d}^{-1}$ 之间, 吴晓东等 ${ }^{[6]}$ 调查太湖水华 期间蓝藻原位生长率所获得的最大值是 $0.37 \mathrm{~d}^{-1}$, 而根据 Robarts 等 ${ }^{[25]}$ 的报道, 不少蓝藻的最大生长率能达 到 $1 \mathrm{~d}^{-1}$ 以上, 由于藻种类、环境条件、观测方法等方面的差异, 各文献的生长率绝对值无法直接比较. 生长率 负值主要发生在水柱的中底层, 以及蓝藻生物量较高或者温度较低的月份, 表明在这些环境下蓝藻死亡率 大于生长率. 水华蓝藻是放氧型的光合细菌, 需要适宜的光强来固定碳源和获得能量, 以合成各种细胞成 分, 用于细胞代谢生长. 所以许多水华蓝藻细胞内都存在可以调节浮力的伪空泡, 以便于它们保持在水体上 层, 获得充足的光照 ${ }^{[26]}$. 在本研究的上、中、下 3 个水柱层中, 蓝藻在上层能获得充足光强, 表现出相对较高 的生长速率, 中层光强较弱, 生长速率相对较低, 而在底层, 由于光照条件很差, 不利于蓝藻生长. 这也表明 巢湖大部分水华蓝藻都来自于中上层蓝藻生长的贡献.

与许多其它研究一致 ${ }^{[27-28]}$, 本研究也发现水温与原位生长率具有一定的正相关性. 但巢湖水华蓝藻原 位生长率较高的时期出现在 4-6 月, 并不是出现在气温和光照强度最高的 7-8 月. 虽然水华蓝藻相对于 其他藻类在高温环境下具有更强的竞争力 ${ }^{[29]}$, 群体胶鞘和类菌狍素氨基酸 (MAAs) 也有助于它们抵御高光 强和紫外光 ${ }^{[30-31]}$, 但过高的温度和光强对水华蓝藻的生长也会产生负面影响 ${ }^{[32]}$. 氮和磷是水华蓝藻生长的 必需营养元素, 对水华蓝藻的生长有着重要的影响, 许多野外的氮磷添加试验都证实了磷是大部分淡水水 体中最重要的限制因子 ${ }^{[33-34]}$. 由于藻类主要利用的是溶解性氮、磷, 而蓝藻生物量较高时, 无法被直接利用 的颗粒态氮、磷会占水体总氮和总磷的较大比重, 因此,本研究选择 TDN 及 TDP 分析营养盐与原位生长率 的相关性. 结果表明原位生长率与 TDP 浓度具有很好的正相关性, 但与 TDN 浓度的相关性不高, 这表明磷 也是巢湖水华蓝藻生长的主要限制因子, 而在现有水平下, 氮浓度的波动对巢湖水华蓝澡生长的影响相对 
较小. 巢湖外源污染负荷大部分来源于流域西部, 这导致巢湖的营养盐水平在空间上表现出由西向东逐步 降低的趋势, 进而使得原位生长率也呈现出相同的趋势. 由此可知, 巢湖蓝藻生物量大部分来自于西部湖区 蓝藻的生长. 原位生长率与表征蓝藻生物量指标的藻蓝素浓度并没有表现出良好的相关性, 在藻蓝素浓度 最高的 7-9 月份, 除西部湖区外, 中、东部 2 个湖区原位生长率均很低. 这是因为过高的初始生物量会抑制 蓝藻种群的进一步增长, 一方面, 蓝藻细胞在生长的同时, 也有许多细胞慢慢衰亡, 当水华蓝藻现存量较高 时, 水体中发生衰亡的藻细胞数量也非常多. 另一方面, 单位水柱能维持的蓝藻生物量是有限的, 蓝藻存量 越高, 越接近饱和,生长空间减少后, 藻细胞的生长也随之受到限制.

富营养化及蓝藻水华问题的彻底解决, 需要流域污染输人控制与生态修复相结合, 不可能一朝一夕完 成. 通过构建蓝藻水华预测体系, 预判水华蓝藻发展状况, 采取针对性的应急处置措施, 可有效减少蓝藻水 华带来的次生灾害及其对周边居民的影响. 蓝藻水华预测的主要内容是预测未来一段时间内蓝藻在特定水 域的生物量, 只有掌握了水华蓝藻的原位生长率规律才能结合环境条件准确估算水华蓝藻生物量. 基于本 研究结果可以对巢湖不同湖区及季节的蓝藻水华发展动态进行初步的研判. 由于原位生长率受到多方面因 素的影响, 通过周年的月度调查, 仅能获得水华蓝藻原位生长率在巢湖的大致规律. 为了更准确地进行蓝藻 水华预测, 需要开展高频的野外调查以及野外控制实验, 同时发展原位生长率的在线监测技术, 获得各因素 对水华蓝藻生长影响的定量化结果, 以精确掌握各种环境条件下水华蓝藻的原位生长率, 用于预测模型参 数率定. 此外, 除了环境因子, 蓝藻的种类和生理状态都会影响其生长速率, 这些因素在将来的相关研究中 都需要考虑.

\section{4 结论}

1) 巢湖水华蓝藻的原位生长率变化范围在 $-1.16 \sim 0.69 \mathrm{~d}^{-1}$ 之间, 表层最高, 中层次之, 底层大部分月份 都为负值; 在空间分布上由高到低依次为西部湖区 > 中部湖区 >东部湖区; 在季节变化上, 春季 (4-6月) 相 对较高, 冬季( $1-2$ 月) 相对较低.

2) 采用 Spearman 相关分析结果表明, 原位生长率与 DTP 浓度和温度均呈正相关, 磷可能是巢湖水华蓝 藻生长的主要限制因子,而在现有水平下,氮浓度的波动对巢湖水华蓝藻生长的影响相对较小.

3) 周年的月度调查仅能获得水华蓝藻原位生长率在巢湖的大致规律. 想要精确掌握各种环境条件下水 华蓝藻的原位生长率, 需要开展高频的野外调查, 并考虑到蓝藻的种类和生理状态.

\section{5 参考文献}

[ 1 ] Huovinen P. Temporal and vertical dynamics of phytoplankton net growth in Castle Lake, California. Journal of Plankton Research, 1999, 21(2) : 373-385. DOI: 10.1093/plankt/21.2.373.

[ 2 ] Li Z, Xie D, Guo JS et al. Preliminary study on in situ growth rate of dominant algae species in Pengxi River of the Three Gorges Reservoir. J Lake Sci, 2012, 24(5) : 746-754. DOI: 10.18307/2012.0516. [李哲, 谢丹, 郭劲松等. 三峡水库 澎溪河典型优势藻原位生长速率的初步研究. 湖泊科学, 2012, 24(5) : 746-754.]

[ 3 ] Davis PA, Walsby AE. Comparison of measured growth rates with those calculated from rates of photosynthesis in Planktothrix spp. isolated from Blelham Tarn, English Lake District. New Phytologist, 2002, 156(2) : 225-239. DOI: 10.1046/j. 1469-8137.2002.00495.x.

[ 4 ] Xu SL, Huang BQ. Photopigment radiolabelling as a tool for determining group-specific phytoplankton photosynthesis rate and growth rate. Journal of Oceanography in Taiwan Strait, 2010, 29(4): 478-487. [徐松立, 黄邦钦. 光合色素标记 法测定不同类群浮游植物的光合速率和生长速率. 台湾海峡, 2010, 29(4) : 478-487.]

[ 5 ] Tsujimura S. Application of the frequency of dividing cells technique to estimate the in situ growth rate of Microcystis (Cyanobacteria). Freshwater Biology, 2003, 48(11) : 2009-2024. DOI: 10.1046/j.1365-2427.2003.01147.x.

[ 6 ] Wu XD, Kong FX. The determination of in situ growth rates of the bloomed Microcystis in Meiliang Bay, Lake Taihu. China Environmental Science, 2008, 28(6) : 552-555. [ 吴晓东, 孔繁翔. 水华期间太湖梅梁湾微囊藻原位生长速率的测 定. 中国环境科学, 2008, 28(6): 552-555.]

[ 7 ] Lin SJ, Chang J, Carpenter EJ. Detection of proliferating cell nuclear antigen analog in four species of marine phytoplank- 
ton. Journal of Phycology, 1994, 30(3) : 449-456. DOI: 10.1111/j.0022-3646.1994.00449.x.

[ 8 ] Yoshida T, Maki M, Okamoto H et al. Coordination of DNA replication and cell division in Cyanobacteria Microcystis aeruginosa. FEMS Microbiology Letters, 2005, 251(1) : 149-154. DOI: 10.1016/j.femsle.2005.07.041.

[ 9 ] Falkowski PG, Owens TG. A technique for estimating phytoplankton division rates by using a DNA-binding fluorescent dye. Limnology and Oceanography, 1982, 27(4) : 776-782. DOI: 10.4319/lo.1982.27.4.0776.

[10] Pratt DM, Berkson H. Two sources of error in the oxygen light and dark bottle Method. Limnology and Oceanography, 1959, 4(3) : 328-334. DOI: 10.4319/lo.1959.4.3.0328.

[11] Wang SM, Dou HS eds. China lakes. Beijing: Science Press, 1998. [王苏民, 窦鸿身. 中国湖泊志. 北京: 科学出版 社, 1998.]

[12] Zhang M, Kong FX. The process, spatial and temporal distributions and mitigation strategies of the eutrophi-cation of Lake Chaohu(1984-2013). J Lake Sci , 2015, 27 (5) : 791-798. DOI : 10.18307/2015.0505. [张民, 孔繁翔. 巢湖富营养化 的历程、空间分布与治理策略(1984-2013 年). 湖泊科学, 2015, 27(5) : 791-798.]

[13] Wang SH, Hang X, Jin XC. Spatial-temporal variations of aquatic environmental factors and their influences to algal blooming in Lake Chaohu. J Lake Sci, 2011, 23(6) : 873-880. DOI: 10.18307/2011.0608. [王书航, 姜霞, 金相灿. 巢 湖水环境因子的时空变化及对水华发生的影响. 湖泊科学, 2011, 23(6) : 873-880.]

[14] Zhang M, Shi XL, Yang Z et al. The variation of water quality from 2012 to 2018 in Lake Chaohu and the mitigating strategy on cyanobacterial blooms. J Lake Sci, 2020, 32(1): 11-20. DOI: 10.18307/2020.0102. [张民, 史小丽, 阳振等. 2012-2018 年巢湖水质变化趋势分析和蓝藻防控建议. 湖泊科学, 2020, 32(1) : 11-20.]

[15] Yan R, Kong FX, Han XB. Analysis of the recruitment of the winter survival algae on the sediments of Lake Taihu by fluorometry. J Lake Sci, 2004, 16(2) : 163-168. DOI: 10.18307/2004.0210. [阎荣, 孔繁翔, 韩小波. 太湖底泥表层越 冬藻类群落动态的苂光分析法初步研究. 湖泊科学, 2004, 16(2) : 163-168.]

[16] Furnas MJ. Net in situ growth rates of phytoplankton in an oligotrophic, tropical shelf ecosystem. Limnology and Oceanography, 1991, 36(1) : 13-29. DOI: 10.4319/lo.1991.36.1.0013.

[17] Feng J, Li Z, Yan B et al. In situ growth rate of dominant algae species in Pengxi River of the Three Gorges Reservoir. J Lake Sci, 2014, 26(2) : 235-242. DOI: 10.18307/2014.0210. [冯婧, 李哲, 间涁等. 三峡水库不同运行阶段澎溪河 典型优势藻原位生长速率. 湖泊科学, 2014, 26(2) : 235-242.]

[18] Yamamoto Y, Tsukada H. Measurement of in situ specific growth rates of Microcystis (cyanobacteria) from the frequency of dividing cells. Journal of Phycology, 2009, 45(5) : 1003-1009. DOI: 10.1111/j.1529-8817.2009.00723.x.

[19] Mowe MAD, Porojan C, Abbas F et al. Rising temperatures may increase growth rates and microcystin production in tropical Microcystis species. Harmful Algae, 2015, 50: 88-98. DOI: 10.1016/j.hal.2015.10.011.

[20] Westwood KJ, Ganf GG. Effect of mixing patterns and light dose on growth of Anabaena circinalis in a turbid, lowland river. River Research and Applications, 2004, 20(2) : 115-126. DOI: 10.1002/rra.725.

[21] Xu H, Paerl HW, Qin BQ et al. Nitrogen and phosphorus inputs control phytoplankton growth in eutrophic Lake Taihu, China. Limnology and Oceanography, 2010, 55(1) : 420-432. DOI: 10.4319/lo.2010.55.1.0420.

[22] Sun J, Ning XR. Marine phytoplankton specific growth rate. Advances in Earth Science, 2005, 20(9): 939-945. [孙军, 宁修仁. 海洋浮游植物群落的比生长率. 地球科学进展, 2005, 20(9) : 939-945.]

[23] Zeng XB. Primary study of pigment-specific rates of phytoplankton growth and microzooplankton grazing in Xiamen western waters. Journal of Yangtze University: Natural Science Edition, 2007, 4(4): 35-38. [曾祥波. 厦门西海域浮游植物不 同色素类群的生长率和摄食死亡率的初步研究. 长江大学学报: 自然科学版, 2007, 4(4) : 35-38.]

[24] Xie P ed. Silver carp, bighead carp and algae bloom control. Beijing: Science Press, 2003: 103-109. [谢平. 鲢、鳙与藻 类水华控制. 北京: 科学技术出版社, 2003: 103-109.]

[25] Robarts RD, Zohary T. Temperature effects on photosynthetic capacity, respiration, and growth rates of bloom-forming cyanobacteria. New Zealand Journal of Marine and Freshwater Research, 1987, 21(3) : 391-399. DOI: 10.1080/00288330. 1987.9516235 .

[26] Oliver RL. Floating and sinking in gas-vacuolate cyanobacteria. Journal of Phycology, 1994, 30(2) : 161-173. DOI: 10. 1111/j.0022-3646.1994.00161.x.

[27] Sabour B, Sbiyyaa B, Loudiki M et al. Effect of light and temperature on the population dynamics of two toxic bloom forming Cyanobacteria—Microcystis ichthyoblabe and Anabaena aphanizomenoides. Chemistry and Ecology, 2009, 25: 277-284. 
[28] Yang Z, Zhang M, Yu Y et al. Temperature triggers the annual cycle of Microcystis, comparable results from the laboratory and a large shallow lake. Chemosphere, 2020, 260: 127543. DOI: 10.1016/j.chemosphere.2020.127543.

[29] Reynolds CS ed. The ecology of phytoplankton. Cambridge: Cambridge University Press, 2006.

[30] Wang Y, Li SS, Li JH et al. Physiological response of Microcystis to solar UV radiation. Acta Ecologica Sinica, 2011,31 (21) : 6532-6539. [汪燕, 李珊珊, 李建宏等. 铜绿微囊藻对紫外辐射的生理代谢响应. 生态学报, 2011, 31(21): 6532-6539.]

[31] Liu ZW, Häder DP, Sommaruga R. Occurrence of mycosporine-like amino acids (MAAs) in the bloom-forming cyanobacterium Microcystis aeruginosa. Journal of Plankton Research, 2004, 26(8) : 963-966. DOI: 10.1093/plankt/fbh083.

[32] Fang TX, Ma ZL. Effects of temperature variation on the growth and photosynthesis of Microcystis aeruginosa. Ecological Science, 2016, 35(6) : 14-23. [方婷轩, 马增岭. 温度变化对铜绿微囊藻 (Microcystis aeruginosa) 生长和光合作用的 影响. 生态科学, 2016, 35(6): 14-23.]

[33] Schindler DW, Hecky RE, Findlay DL et al. Eutrophication of lakes cannot be controlled by reducing nitrogen input: Results of a 37-year whole-ecosystem experiment. PNAS, 2008, 105(32) : 11254-11258. DOI: 10.1073/pnas.0805108105.

[34] Coveney MF, Lowe EF, Battoe LE et al. Response of a eutrophic, shallow subtropical lake to reduced nutrient loading. Freshwater Biology, 2005, 50(10) : 1718-1730. DOI: 10.1111/j.1365-2427.2005.01435.x. 